\title{
Protocetid cetaceans (Mammalia) from the Eocene of India
}

\author{
Sunil Bajpai and J.G.M. Thewissen
}

\begin{abstract}
Protocetid cetaceans were first described from the Eocene of India in 1975, but many more specimens have been discovered since then and are described here. All specimens are from District Kutch in the State of Gujarat and were recovered in deposits approximately 42 million years old. Valid species described in the past include Indocetus ramani, Babiacetus indicus and $B$. mishrai. We here describe new material for Indocetus, including lower teeth and deciduous premolars. We also describe two new genera and species: Kharodacetus sahnii and Dhedacetus hyaeni. Kharodacetus is mostly based on a very well preserved rostrum and mandibles with teeth, and Dhedacetus is based on a partial skull with vertebral column. The Kutch protocetid fauna differs from the protocetid fauna of the Pakistani Sulaiman Range, possibly because the latter is partly older, and/or because it samples a different environment, being located on the trailing edge of the Indian Plate, directly exposed to the Indian Ocean.
\end{abstract}

Sunil Bajpai. Department of Earth Sciences, Indian Institute of Technology, Roorkee 247667, Uttarakhand, India. Current address: Birbal Sahni Institute of Palaeobotany, Lucknow 226007, Uttar Pradesh, India. director@bsip.res.in; sunilbajpai2001@yahoo.com.

J.G.M. Thewissen (corresponding author). Department of Anatomy and Neurobiology, Northeast Ohio Medical University, Rootstown, Ohio 44272, U.S.A. thewisse@neomed.edu.

Keywords: Eocene; Mammalia; Cetacea; India; New species; New genus

\section{INTRODUCTION}

The earliest cetaceans, pakicetids and ambulocetids are only known from the Eocene of India and Pakistan (reviewed by Thewissen et al., 2009). These families are followed, in time as well as on the cladogram, by remingtonocetids and protocetids. Unambiguous remingtonocetid fossils are also only known only from India and Pakistan (Sahni and Mishra, 1975; Kumar and Sahni, 1986; Gingerich et al., 1995b; Bajpai and Thewissen,
1998, 2000; Thewissen and Hussain, 1998) and many specimens of the remingtonocetine genera Remingtonocetus (Bajpai et al., 2011), Dalanistes (Thewissen and Bajpai, 2001) and the andrewsiphiine genera Andrewsiphius and Kutchicetus (Thewissen and Bajpai, 2009) have been recovered in Kutch (Gujarat, India). Remingtonocetids had small eyes and large middle ear cavities. Remingtonocetines and andrewsiphiines are both common in localities indicative of murky water, but

http://zoobank.org/6A475A48-F702-49BB-8A8F-1B732123348A

PE Article Number: 17.3.34A

Copyright: Paleontological Society October 2014

Submission: 31 January 2014. Acceptance: 11 September 2014

Bajpai, Sunil and Thewissen, J.G.M. 2014. Protocetid cetaceans (Mammalia) from the Eocene of India. Palaeontologia Electronica Vol. 17, Issue 3;34A; 19p;

palaeo-electronica.org/content/2014/914-whales-from-india 
Remingtonocetus also lived in more clear water localities (Thewissen and Bajpai, 2009).

Protocetids are found in many continents, including Africa (Kellogg, 1936; Williams, 1998; Bianucci and Gingerich, 2011; Gingerich and Cappetta, 2014), North America (Hulbert et al., 1998; Geisler et al., 2005; Uhen, 2008, 2014a, 2014b), and South America (Uhen et al., 2011). Apparently then, protocetids were the first cetaceans able to cross oceans, and to colonize tropical and subtropical oceans.

Several genera of protocetids are known from the desert of Kutch in western India and the mountains of the Sulaiman Range in Pakistan. From Kutch, Indocetus ramani Sahni and Mishra, 1975, Babiacetus indicus Trivedi and Satsangi, 1984, Babiacetus mishrai Bajpai and Thewissen, 1998, and Gaviacetus sahnii Bajpai and Thewissen, 1998, have been reported. Specimens initially identified as Protocetus (Sahni and Mishra, 1975) have been reassigned later to Remingtonocetus (Kumar and Sahni, 1986). In the Sulaiman Range, there may be nine genera with 10 species of Eocene whales: Rodhocetus kasranii Gingerich et al., 1994 (spelling amended by Gingerich et al., 2001a); Babiacetus indicus Trivedi and Satsangi, 1984 (reported by Gingerich et al., 1995a), Takracetus simus Gingerich et al., 1995b; Gaviacetus razai Gingerich et al., 1995b; Artiocetus clavis Gingerich et al., 2001b; Rodhocetus balochistanensis Gingerich et al., 2001b; Qaisracetus arifi Gingerich et al., 2001a; Makaracetus bidens, Gingerich et al., 2005, and Maiacetus inuus Gingerich et al., 2009. Specimens of Indocetus reported from the Sulaiman Range by Gingerich et al. (1993) have now been reassigned to Remingtonocetus (Gingerich et al., 1995b).

The Kutch deposits with fossil cetaceans were dated to 42 million years ago by Ravikant and Bajpai (2010). The localities in the Sulaiman Range have some species in common with those in Kutch, and it appears clear that some of the faunal differences are due to environmental differences between the two regions. Here we report new protocetid cetaceans from Kutch and review the already described species from India.

\section{SYSTEMATIC PALAEONTOLOGY}

\author{
Class MAMMALIA Linnaeus, 1758 \\ Order CETACEA Brisson, 1762 \\ Family PROTOCETIDAE Stromer, 1908 \\ Genus Indocetus Sahni and Mishra, 1975
}

Type species. Indocetus ramani Sahni and Mishra, 1975 , by original designation.
Differential diagnosis. Indocetus is a medium-sized protocetid, with teeth larger than most protocetids from the Indian continent, but smaller than those of Kharodacetus, and only slightly larger than teeth of Rodhocetus. The orbit is barely elevated above the palate (unlike Kharodacetus and Dhedacetus). Indocetus has a flat supraorbital shield with large orbits, similar to all other protocetids and different from pakicetids, ambulocetids and remingtonocetids.

Discussion. Gingerich et al. (1994) diagnosed Rodhocetus as distinct from Indocetus based on the convexity of the posterior surface of the exoccipital, the shorter cervical vertebrae, unfused sacral vertebrae and the shorter femur. However, the postcranial elements on which the Indocetus comparisons are based have been reassigned to other taxa, and these elements are not known for Indocetus. This leaves the exoccipital as the only diagnostic feature. It is possible that the exoccipital shape constitutes a consistent and sharp difference between Rodhocetus and Indocetus, but it is also possible that this difference does not merit distinction of separate genera. The $\mathrm{m} 1$ crown of the specimen referred to Indocetus below (IITR-SB 2986 ) is $125 \%$ as large, in linear dimensions, as the same tooth of Rodhocetus kasrani (GSP-UM 3012, Gingerich et al., 1995b). This size difference may merit distinction at the specific level, but is probably not a diagnostic character at the genus level. Based on the limited amount of available evidence, it is likely that Rodhocetus is a junior synonym of Indocetus, however, we stop short of synonymizing these taxa, as a more detailed comparison of holotypes and a study of the variability of South Asian protocetids are needed. At present, it is preferable to maintain the status quo.

Gingerich et al. (2001b, supplementary information) showed that there are significant differences in the rostrum shape of the Indo-Pakistani protocetids. The shape of the rostrum of Indocetus matches that of Rodhocetus. The rostrum of Artiocetus, Takracetus and Maiacetus (Gingerich et al., 2009) is broader, whereas that of Gaviacetus and Babiacetus (based on its lower jaws) is narrower. In Makaracetus the rostrum is downturned (Gingerich et al., 2005), unlike any other protocetid. It is likely that rostrum differences reflect differences in feeding and quantification of these differences based on original, undeformed material may expose subtle ecological differences among these taxa. 


\section{Indocetus ramani Sahni and Mishra, 1975 Figure 1.1-4}

Holotype. LUVP 11034, fragments of orbits with palate, interorbital region, and ear region with crown for one molar.

Other material. IITR-SB 2000-33, left mandible with dp3 and dp4, Babia Hill; IITR-SB 2986, left mandible with dp3 fragment, dp4, m1, and unerupted m2; Rato Nala. IITR-SB 4001, palatal/orbital fragment with crowns for right P3-M1, Rato Nala; VPL 1014, right tympanic, Bajpai and Thewissen (1998); VPL 1017 , endocast of cranial cavity, palatal, interorbital fragment, Bajpai et al. (1996); VPL 1018, endocast of cranial cavity, Bajpai et al. (1996).

Type locality. Rato Nala, $1 \mathrm{~km}$ north of the village of Harudi.

Type stratum. Harudi Formation, Eocene, around 42 million years old.

Diagnosis. Same as for genus.

Description. IITR-SB 4001 shows alveoli for P2 and crowns for P3 to M1 (Figure 1.3-4, Table 1). There are two alveoli for P2, followed by a diastema, whereas no diastemata occur between P3 and M1. P3 and P4 are similar in shape. They lack a protocone, but have a large lingual bulge, similar in size to that of Babiacetus (Gingerich et al., 1995a). The bulge is located on the posterior part of the tooth. The tooth has a large paracone that is placed posteriorly and a much lower but distinct metacone. These are proportionally similar to Babiacetus. The preparacrista slopes less than the postparacrista. The cingulum is complete lingually, but interrupted labially.

M1 has a large protocone lobe, but it is worn, and it cannot be ascertained whether there was a protocone. Wear similar to this is also present in the only tooth that is part of the holotype (LUVP 11034), identified as M1. The paracone is large and situated on the anterior part of the tooth, while the metacone is lower than the paracone, but remains a distinct cusp that projects from the postparacrista. The relative size of these cusps is similar to those of Georgiacetus (Hulbert et al., 1998).

The palate is concave rostro-caudally, bending sharply ventral caudal to the teeth, as in the holotype, and there are embrasure pits between P3 and P4 and behind M1, but not between P4 and M1. The dorsal rim of the orbit is preserved and indicates that the orbit was placed laterally underneath a large supraorbital shield as in other protocetids, such as Protocetus and Carolinacetus (Geisler et al., 2005). The posterior edge of this shield extends sharply mediolaterally. The postorbital process is blunt and triangular and is indented ventrally by a deep groove that contained the nerves to the eye and orbit. The face is low, with the orbit placed only slightly above the palate, unlike Kharodacetus (see below).

IITR-SB 2986 (Figure 1.1-2) is a well-preserved mandible for Indocetus ramani. The caudal end of dp3 is preserved, and it shows that a small cusp is present at the end of the postprotocrista. The dp4 has four cusps that are lined up from rostral to caudal, and are connected by a sharp crest. The rostral cusp is the lowest, and the second cusp the highest, the third and fourth cusp decrease in size from the second cusp. The lingual cingulum is complete, and the labial cingulum is damaged for as far as it can be studied. The $\mathrm{m} 1$ bears two cusps, a high protoconid on the trigonid and a low hypoconid. The rostral face of the protoconid is concave, bounded by a sharp lingual crest and a much weaker labial crest. Both of these crests ascend the protoconid partially. A sharp crest descends from the protoconid caudally and is continued over the rostral and caudal aspect of the hypoconid. Only the tip of $\mathrm{m} 2$ is erupted.

The mandible shows a gently ascending coronoid process, and a strongly dorso-ventrally convex mandibular condyle that faces caudally, similar to that of other protocetids, such as Georgiacetus (Hulbert et al., 1994). The mandibular foramen is large, $45 \mathrm{~mm}$ at its opening, and covers the depth of the jaw, grooving the mandible caudal to it. The lateral mandibular wall at dp3 is $7.4 \mathrm{~mm}$ thick.

IITR-SB 2000-33 is a deciduous mandible that is gypsified. The morphology of dp4 is not different from that in IITR-SB 2986, but the crown of dp3 is also preserved. It is a narrow and long tooth, proportionally narrower than dp4. Dp3 is triangular in lateral view, with enamel extending basal over the roots, but not in the middle section of the tooth, giving the tooth the appearance of a yoke. Two alveoli for $\mathrm{m} 1$ indicate that this tooth had erupted and was lost post mortem.

Discussion. Although it was the first Eocene cetacean described and recognized from the Indian Subcontinent (Sahni and Mishra, 1975), Indocetus is poorly known. We here increase the hypodigm for the species with a skull fragment that includes tooth crowns (IITR-SB 4001) and that is referred to the species on the basis on the similarity of the tooth crown of M1 with that of the holotype, and the shape of the orbit and face. Two mandibles with deciduous teeth are also referred to Indocetus (IITR-SB 2000-33 and 2986) based on their similarity in general size and occlusional fit with the maxillae, Kumar and Sahni (1986) and Bajpai and 

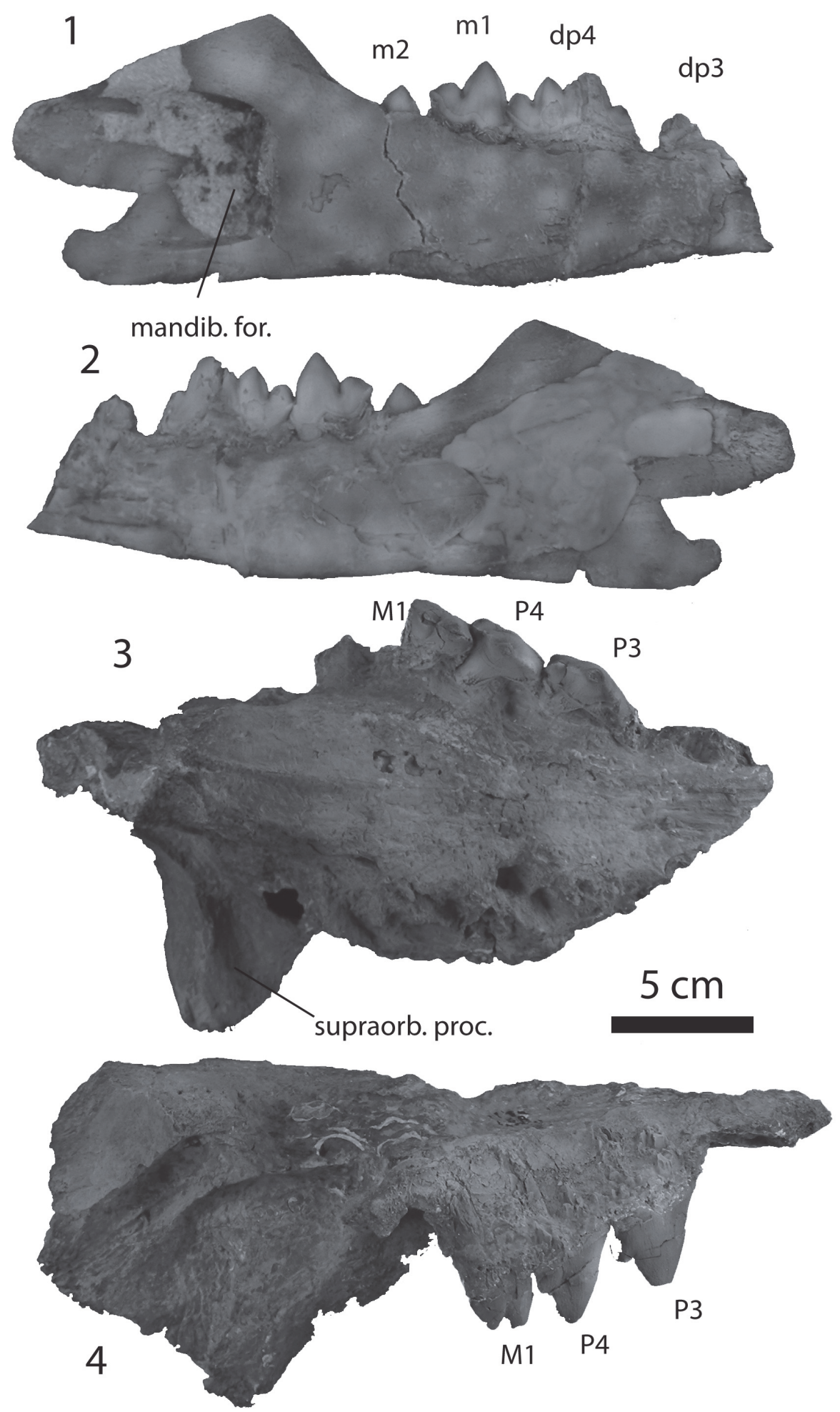

FIGURE 1. Indocetus ramani. 1-2, IITR-SB 2986 in lingual and labial view, left mandible with fragment of d3, complete $\mathrm{d} 4$ and $\mathrm{m} 1$, and unerupted $\mathrm{m} 2$. This specimen preserves the mandibular foramen (mandib. for.). 3-4, IITR-SB 4001 in palatal and right lateral view, palate and orbit with right P3-M1, showing supraorbital process (supraorb. proc.). 
TABLE 1. Dental measurements (in $\mathrm{mm}$ ) for Indian protocetids, $\mathrm{W}=$ width, $L=$ =length.

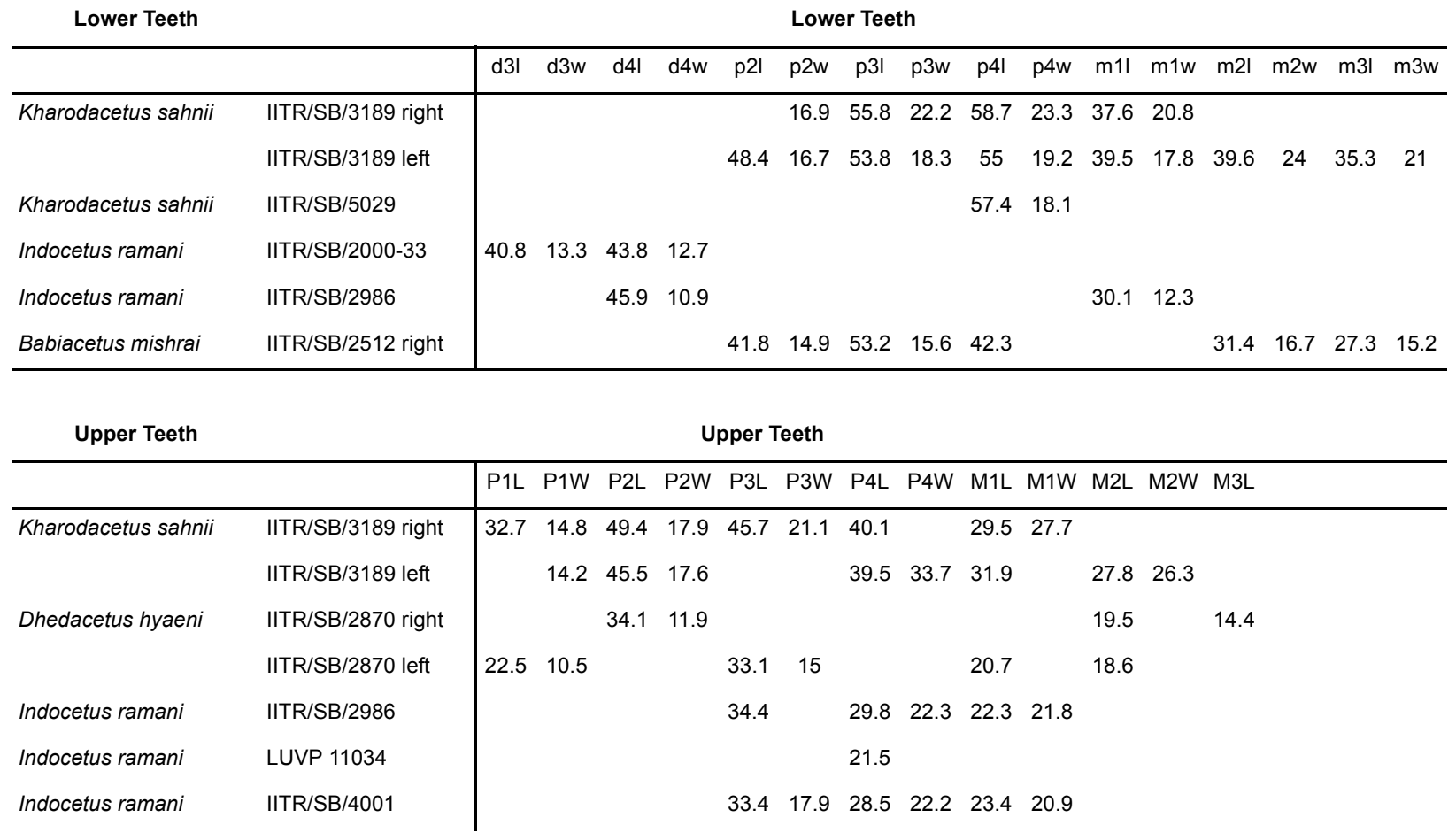

Thewissen (1998) described the holotype, and Bajpai et al. (1996) the cranial endocast. Spoor et al. (2002) studied CT scans of the ear region and determined that the semicircular canals of Indocetus, when scaled for body size, are similar in size to those of modern cetaceans, and much smaller than those of land mammals and pakicetid whales. Nummela et al. $(2004,2007)$ discussed middle ear morphology and function in detail, finding that the ear of Indocetus showed a number of adaptations for underwater hearing, but that these adaptations also occurred in remingtonocetids, which are more basal on the cetacean cladogram (Geisler et al., 2005; Uhen et al., 2011).

Indocetus ramani is similar morphologically to Rodhocetus kasrani (Gingerich et al., 1994), but the $\mathrm{m} 1$ of the former is larger, and Gingerich et al. (1994) noted a difference in the exoccipital (see discussion under genus). Gingerich et al. (1993) referred a number of specimens to Indocetus ramani, but the specimens among these that are identifiable were later reinterpreted as Remingtonocetus (GDP-UM 3009 and 3015), Dalanistes (GSP-UM 11) and Rodhocetus (GSP-UM 1853, Gingerich et al., 1995b). VPL 1023, a maxilla with fragments of P3-M3 was referred to Indocetus ramani by Bajpai and Thewissen (1998), but is here referred to Babiacetus mishrai. The P3 and $\mathrm{P} 4$ length of this specimen are greater than in IITR-
SB 4001, while the M1 length is less than IITR-SB 4001.

Genus Babiacetus Trivedi and Satsangi, 1984

Type species. Babiacetus indicus Trivedi and Satsangi, 1984, by original designation.

Differential diagnosis. Babiacetus has robust tooth crowns with lower premolars that are relatively wide compared to the lower molars (Table 1) and a mandibular symphysis that reaches caudal to $\mathrm{p} 2$.

Discussion. Babiacetus differs from other IndoPakistani protocetids in the extreme narrowness of its mandibles, with the mandibular symphysis reaching far caudally, and the broad contact between left and right mandible. Mandibles of other protocetids diverge rostral to this. Gingerich et al. (2001b) described difference in rostrum shape between protocetids from the Indian subcontinent (see discussion of Indocetus). Babiacetus is a rare cetacean in Kutch, and no new specimens are referred to it in this paper.

Two species of Babiacetus have been described: Babiacetus indicus Trivedi and Satsangi, 1984 and Babiacetus mishrai Bajpai and Thewissen, 1998, but these were based on only three specimens. Mandibles and a fragmentary skull of $B$. indicus are known from the Pakistani Sulaiman Range (GSP-UM 3005; Gingerich et al., 


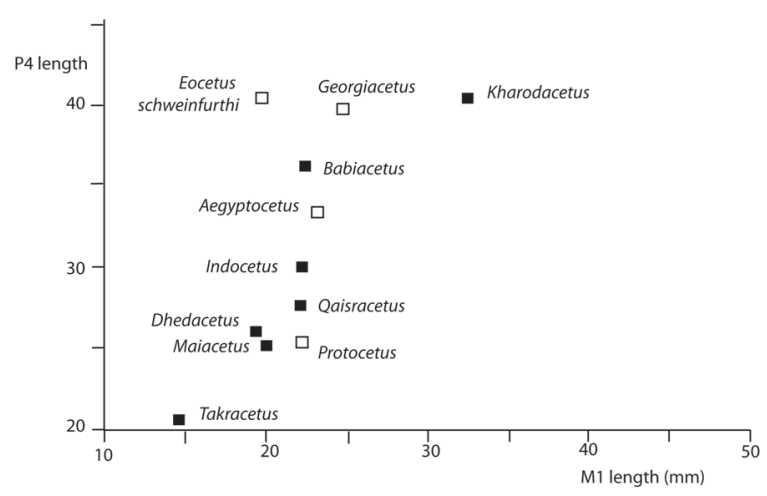

FIGURE 2. Length of $M 1$ plotted against length of $P 4$ for some protocetids, black squares are Indo-Pakistani species, white squares are from other continents. Tooth size data in this figure are based on casts or values given in Gingerich et al. (1995b, 2001b, 2005), Hulbert et al. (1998), and Bianucci and Gingerich (2011).

1995a), and from Kutch (GSI 19647; Trivedi and Satsangi, 1984, see Gingerich et al., 1995a), and mandibles of $B$. mishrai are known from Kutch (IITR-SB 2512; Bajpai and Thewissen, 1998). B. mishrai has a shorter mandible, lacks diastemata between lower premolars and has a single-rooted $\mathrm{p} 1$, unlike $B$. indicus. VPL 1023 is a maxilla with fragments of P3-M3 that was referred to Indocetus ramani by Bajpai and Thewissen (1998), but is here referred to Babiacetus mishrai based on the proportions of its premolars and their size.

\section{Genus Kharodacetus, new genus}

zoobank.org/2E46C3A7-450C-40F6-9958-D36EEEAB3CA1

Type and only species. Kharodacetus sahnii (Bajpai and Thewissen, 1998).

Differential diagnosis. Kharodacetus is a large protocetid, with large premolars and molars, larger than any previously described Indo-Pakistani protocetid (Figure 2). Kharodacetus has a flat supraorbital shield with large orbits, similar to all other protocetids and different from pakicetids, ambulocetids and remingtonocetids. Kharodacetus has a long, relatively broad snout (snout is narrower in Gaviacetus and Makaracetus, broader in Takracetus), its orbit is high above the palate (unlike Indocetus), the premolars are large and robust (unlike Rodhocetus, Qaisracetus, Makaracetus and Gaviacetus). The molars have a large protocone (unlike Babiacetus) and a large metacone (unlike Maiacetus), and are, relative to $\mathrm{P} 4$, longer than in other protocetids (Figure 2).

Derivation of name. Kharodacetus is named for the locality where the most complete dental specimen was found (IITR-SB 3189): the Kharoda locality of Kutch. Note that Kharoda is not the type locality for this species. The suffix -cetus means whale in Latin.

Discussion. Gaviacetus sahnii was described by Bajpai and Thewissen (1998) on the basis of a skull lacking teeth and part of the rostrum (VPL 1021). The rostrum fragment that was preserved led us to believe that the snout was similar to that of Gaviacetus razai from the Sulaiman Range. Discovery of a new specimen with a complete rostrum and well-preserved teeth (IITR-SB 3189), indicates that rostrum shape is different from Gaviacetus razai. Hence, we here propose a new genus to include G. sahnii.

Kharodacetus sahnii (Bajpai and Thewissen, 1998)

Figure 3.1-5, Figure 4.1-4

Holotype. VPL 1021, fragmentary skull with braincase, intertemporal region, orbits and palate, fragment of rostrum, and left and right P2. This specimen was described by Bajpai and Thewissen (1998) as Gaviacetus sahnii.

Type locality. Rato Nala between villages of Baranda and Harudi, $1 \mathrm{~km}$ north of the latter; Kutch District, Gujarat, India. Coordinates for this locality are: 23031'43"N, 68041'08"E.

Type stratum. Harudi Formation, Eocene, around 42 million years old.

Diagnosis. Same as for genus.

Derivation of the name. Named for Ashok Sahni, who contributed greatly to paleontology in India.

Other material. IITR-SB 3189, rostrum with orbits and interorbital region found occluded with upper and lower jaws from Kharoda (23030'88" $\mathrm{N}$, 68.43'33"E). IITR-SB 5029, mandible with crown of p4 and roots or alveoli for i3-p3, m1-m3 from Rato Nala.

Description. The holotype was described in detail by Bajpai and Thewissen (1998, figures 7C-D, and $8)$. The present description is based on the holotype, IITR-SB 3189 and IITR-SB 5029.

The dental formula is 3.1.4.?/?.?.4.3. The absence of M3 was inferred for this species based on the shape of the maxilla by Bajpai and Thewissen (1998), and subsequently doubted by Geisler et al. (2005). Just like the previously described specimen, the maxilla of the new specimen (IITRSB 3189) is slightly damaged posterior to M2, but this specimen preserves crowns for left and right M1-2. There is no indication from the maxilla that M3 was present, and $\mathrm{m} 3$ lacks wear facets that would have been caused by M3. Based on the shape of the fossil, it is likely that M3 was absent, but this cannot be determined with certainty. If this tooth were present, it would have been very small. 

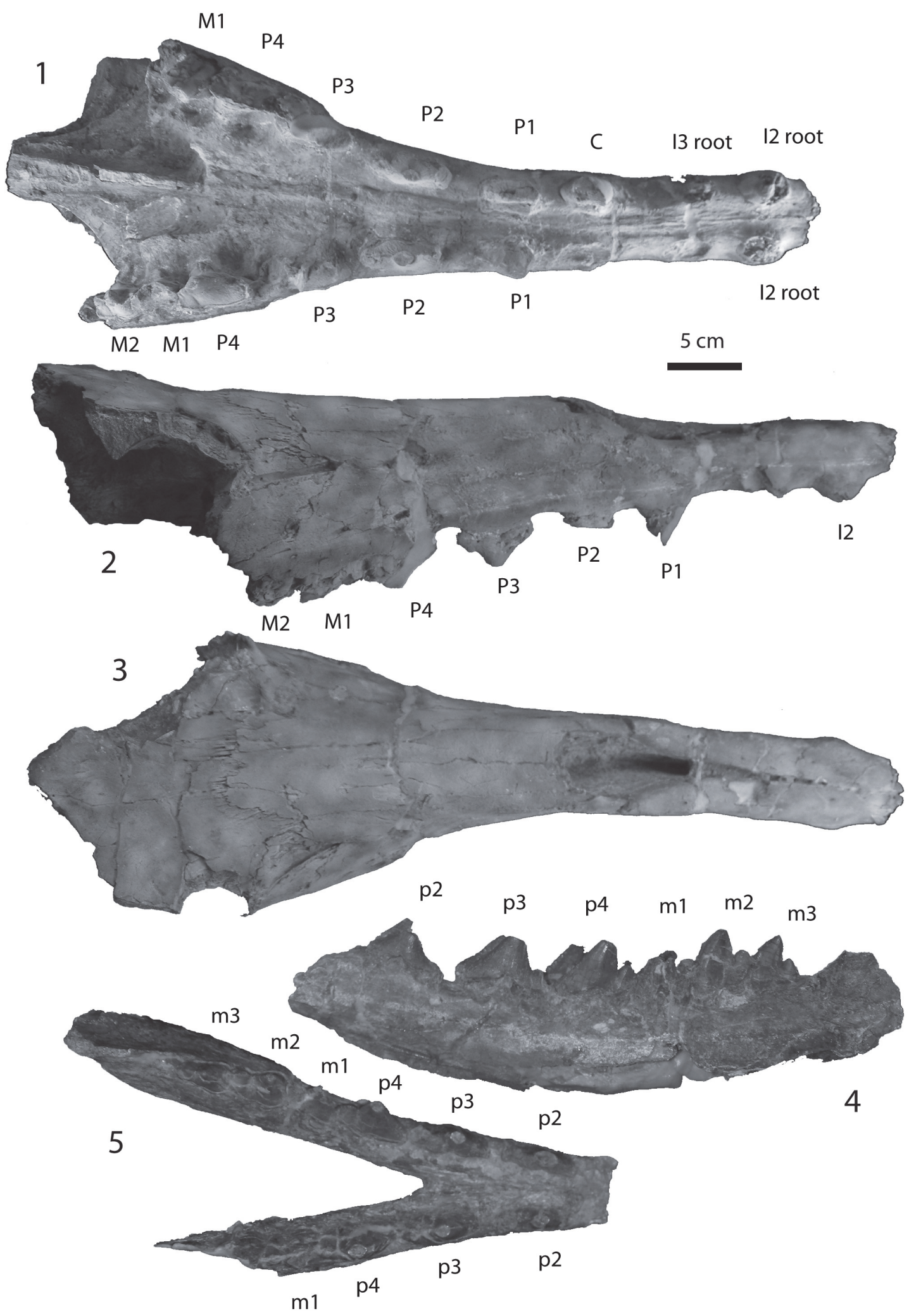

FIGURE 3. Kharodacetus sahnii. 1-5, IITR-SB 3189, rostrum in occlusal, right lateral, and dorsal view (1-3), and mandibles in left lateral and occlusal view (4-5). 


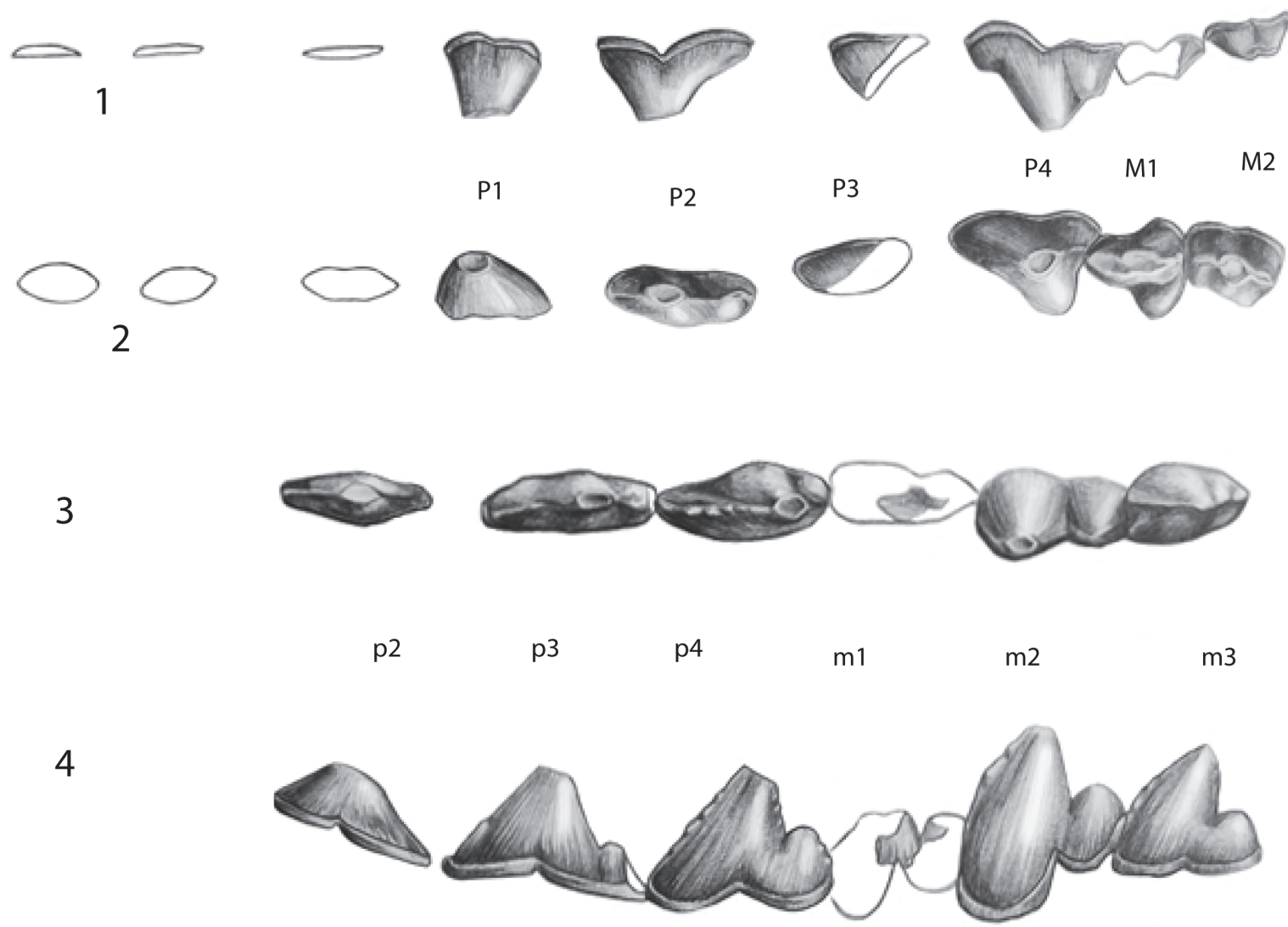

FIGURE 4. Kharodacetus sahnii. 1-4, IITR 3189, left upper dentition in labial and occlusal view (1-2), and left lower dentition in occlusal and labial view (3-4).

All teeth are robust, and worn to some degree in all specimens, with wear being different on the left and right side of IITR-SB 3189. The enamel is crenulated.

In the upper dentition, diastemata occur between all teeth from I1 to P4. There are no diastemata between teeth from P4 to M2, and left and right $\mathrm{I} 1$ are in contact with each other. Only roots are preserved for incisors. Alveoli for the incisors are similar in size and oval in shape. The canine alveolus is somewhat larger, and its alveolus elongate, with some constriction that implies that the root was partly divided. The first upper and second premolars are double-rooted. P1 is oval in crosssection, and its cusp is placed on the rostral part of the tooth. Pre- and postparacrista descend the paracone anteriorly and posteriorly. The P2 is longer than $\mathrm{P} 1$, its preparacrista ends in a small cusp near the rostral base of the tooth. P2 also has a caudal extension, and the postparacrista reaches a cusp located on this extension. On the palatal side, the cingulum bulges lingually, just caudal to the paracone. On P3, the protocone lobe is located in this position. In the holotype description, Bajpai and Thewissen (1998) identified two isolated premolars as left and right P1. Based on the new specimen, it is clear that these are in fact $\mathrm{P} 2$.

$\mathrm{P} 3$ is similar to $\mathrm{P} 2$, with a protocone lobe which lacks a protocone. The preparacone crista slopes distinctly less than the postparacone crista (IITR-SB 2870), and the protocone lobe is located caudolingual to the paracone. Low on the postparacone crista is a metacone that is much smaller than the paracone. The metacone projects somewhat from the postparacrista. The morphology of P4 is similar to that of P3, but the protocone lobe is larger and the metacone is located higher on the postparacrista. P4 is by far the largest tooth in the upper jaw.

The first and second upper molar are preserved on the left side, but only M1 on the right side. This molar is relatively long, when compared to P4 (Figures 2 and 4). These molars have a protocone lobe, set below most of the crown on the lin- 
gual side of the metacone. Extensive wear on M1 makes it impossible to determine if the protocone lobe bore a cusp, but on M2 this cusp is clearly absent. The tips of the labial cusps are also worn in $M 1$, but grooves set off the metacone from the paracone, and it is likely that each of these cusps had a distinct apex. On M2, the metacone is distinct, but lower than the paracone. A cingulum is present on the caudal and labial side of M2.

Crowns of left and right p2 to $\mathrm{m} 3$ are also preserved in IITR-SB 3189. All these teeth are tworooted. The premolars are triangular teeth, with a protoconid that is the largest feature on the tooth and pre- and postprotocristids descending from it. Although tooth length does not differ greatly from p2 to p4, the height of the protoconid does increase, and as a result the anterior and posterior slopes are steeper in p4 than in p2 and p3. The preprotocristid bears several small cuspules in these premolars, and one of these is especially conspicuous in the left p3. The hypoconid is present in all these premolars, and is largest in p4, positioned on a separate talonid that is conspicuously narrower than the trigonid. Lingual and labial cingulids are also present. In another specimen (IITR-SB 5029), the crown for $p 4$ is also preserved. This tooth is larger than that of IITR-SB 3189, but similar in morphology. Wear in IITR-SB 5029 has progressed beyond that in IITR-SB 3189, and the anterior part of the tooth is deeply worn.

The m1-3 are present in IITR-SB 3189. The trigonid of $\mathrm{m} 1$ is badly worn, but in the other molars it consists of a single cusp, the protoconid. A crenulated crest descends from the protoconid rostrolingually to the cingulid. A weaker crest occurs rostrolabially, causing the rostral side of the molars to be concave. The talonid bears a single cusp, the hypoconid. A cingulum is present in all lower molars, it is lingually somewhat stronger than labially. The $\mathrm{m} 2$ is the longest molar.

Only fragments remain of the mandible of IITR-SB 3189. These show that the mandibular foramen was probably as deep as the mandible, and that the ascending ramus projected well dorsal to the teeth. The mandibular symphysis reached caudal to the level of $\mathrm{p} 3$ at the base of the mandible (Figure 3). On the occlusal side, the mandibular symphysis is fused as far caudal as the anterior side of $\mathrm{p} 2$.

Left and right side of the palate come together in a median crest, and there are embrasure pits behind P3, P4 and M1. The last of these is deeper than the others. There is no anterior palatine foramen on the palate, and the suture between pre- maxilla and canine is immediately anterior to the canine. The suture between maxilla and palatine ends medial to P2. The caudal side of the palate is damaged.

The nasal opening opens over $\mathrm{P} 1$, and is surrounded by premaxilla and nasals. The most posterior extent of the premaxilla on the face is dorsal to the diastema between P3 and P4. The maxilla has a contact with the frontal, and the supraorbital foramen is located over P4. The lacrimal is rectangular on the face, approximately 1.5 times as long as high. The lacrimal touches the nasals at a single point, anterior to the orbit. An exposed lacrimal canal is visible on the right side, exposure is shorter on the left side. Small circular depressed areas occur on the right maxilla below the lacrimal on the right side and near the left lacrimal. These may be puncture marks related to fighting or scavenging. The left and right nasals reach caudal in the midline to the level of mid-orbits.

The orbit is large, approximately $5 \mathrm{~cm}$ in diameter, and a cone shaped depression is directed caudal from it. Dorsal to this, in the intertemporal region, is the temporal fossa, and the maxillary sinus is exposed due to breakage on the right side dorsal to M2. A cross-section of the canal for the olfactory tract is visible on the caudal side of the specimen.

The holotype of Kharodacetus sahnii (VPL 1021) includes the best braincase known for the species. The glenoid is concave rostrocaudally. The postglenoid process is restricted to the lateral side of the glenoid, medially it is interrupted to allow the fat pad of the mandible to pass. The caudal side of the postglenoid process is indented by the external auditory meatus. The external auditory meatus indents from ventral the squamosal, and this groove widens laterally. The part of the squamosal caudal to the external auditory meatus is about $1 \mathrm{~cm}$ thick and bears a deep oval depression. Posterior to this, the squamosal has a broad suture with the mastoid. The mastoid process projects more ventral than either squamosal or paroccipital, being wedged between those bones. Ventrally the mastoid widens and covers the ventral part of the paroccipital process. A small sutural bone is inserted on the suture between mastoid and paroccipital process. In caudal view, the paroccipital process is squared and bears some shallow depressions on its occipital face.

Discussion. Kharodacetus is the largest protocetid from Kutch (Figure 2) and is indeed one of the largest known protocetids known. In addition to overall size, its jaws and teeth are also robust, with 
lingual and labial enamel faces of premolars bulging, making cusps blunt and broad. This is in contrast to other Indian protocetids for which premolars are known, such as Indocetus and Dhedacetus, where lingual and labial enamel faces converge at sharper angles, giving the cusp a more slender outline.

We here refer two new specimens to the species. One of these (IITR-SB 3189) is a rostrum found with occluded mandibles that matches the type specimen in the shape of the orbits, the supraorbital region and the face. The second (IITR-SB 5029 ) is a mandible with a single, poorly preserved tooth, but the morphology of that tooth matches one of the crowns in IITR-SB 3189 in size and shape, and is unlike all other Indian protocetids.

In Kutch, isolated braincases and endocasts of a large protocetid are found regularly, and it is likely that most of these pertain to Kharodacetus, but positive identification is not possible. In contrast, it is rare to find orbits and rostra of protocetids in Kutch, suggesting that protocetid rostra do not fare well during fossilization. This contrasts remingtonocetid rostra, which are common in Kutch.

Genus Dhedacetus, new genus zoobank.org/DA9C0797-CDD9-46AE-AB22-273B401BF6E4

Type and only species. Dhedacetus hyaeni, new species.

Differential diagnosis. Dhedacetus is a mediumsized protocetid, with premolars and molars similar in size to the larger protocetids described before from the Indian continent (namely Babiacetus, Rodhocetus, Maiacetus). As in Kharodacetus, Dhedacetus has a long, relatively broad snout (snout is narrower in Gaviacetus and Makaracetus, broader in Takracetus). In Dhedacetus, the orbit is high above the palate (unlike Indocetus and Babiacetus), the premolars are large (unlike Rodhocetus, Qaisracetus, Makaracetus, and Gaviacetus) and gracile (unlike Kharodacetus). The molars have a large protocone (unlike Babiacetus) and metacone (unlike Maiacetus). Kharodacetus is similar to all other protocetids and differs from pakicetids, ambulocetids and remingtonocetids by having a flat supraorbital shield with large orbits. It differs from basilosaurids in retaining M3.

Derivation of name. Dhedacetus is named for the type locality, the name of which, Dhedadi, is abbreviated for use as a genus name. The suffix -cetus means whale in Latin.

Discussion. Dhedacetus represents a new genus of protocetid from the middle Eocene of the Indian subcontinent. Indo-Pakistani protocetids share retracted nasal openings, supraorbital shield and molars that are larger than the premolars, and most also display a narrow snout with large incisors.

Dhedacetus hyaeni new species

Figures 5.1-5, 6.1-2, 7.1-9, 8.1-2

zoobank.org/B55ABF8F-728C-4F48-BF55-38D6110A888C

Holotype. IITR-SB 2870, fragmentary skull with braincase, interorbital region, orbits and palate, rostrum, left $\mathrm{I1}$, left and right $\mathrm{P} 2$, right $\mathrm{P} 3$, root of right $\mathrm{C}$, left $\mathrm{P} 1$, right $\mathrm{P} 2$, left $\mathrm{P} 3-\mathrm{M} 2$ and right $\mathrm{M} 2-3$. This specimen also includes approximately 29 fragmentary or complete vertebrae.

Type locality. Type locality is a 2.1 kilometres east of the village of Dhedadi (23046'42"N, 68047'16"E). Type stratum. Harudi Formation, Eocene, around 42 million years old.

Diagnosis. Same as for genus.

Derivation of the name. Named for the striped hyenas that live at the type locality.

Other Material. IITR-SB 2625, 10 articulated caudal vertebrae, with complete neural arches and some hemal arches, from Rato Nala.

Description. The snout of the holotype is narrow, its height similar to its width (Figure 5). The palate widens at the diastema between p2 and p3, and the infraorbital canal opens dorsal to this. A jagged suture between premaxilla and maxilla is visible just rostral to the canine. The position of the nostrils is unclear since this part of the skull was not recovered. Given that the part rostral to the canine and caudal to $\mathrm{P} 2$ are preserved, the nasal opening must be between canine and P2.

The palate is more deeply recessed lingual to the molars than in Kharodacetus, presumably to receive the trigonids of the lower molars when the mouth is closed. The caudal palate is somewhat concave rostro-caudally, similar to Indocetus. The ventral wall of the nasopharyngeal duct is ossified and continuous with the palate. Depressions for the medial pterygoid muscles indent the nasopharyngeal duct reaching the midline caudally. Orbital structures are damaged, but the optic foramen is clearly preserved on the left side of the specimen.

On the face, the nasals extend caudally forming about one third of the height of the face. The sutures of the lacrimal bone are unclear. There is lacrimal tubercle located ventral to a groove that crosses the orbital rim. The supraorbital shield is deformed, but formed the widest part of the rostral part of the skull. Temporal lines form its caudal edge, and they converge toward to the midline. Left and right temporal lines unite to form the sagittal 

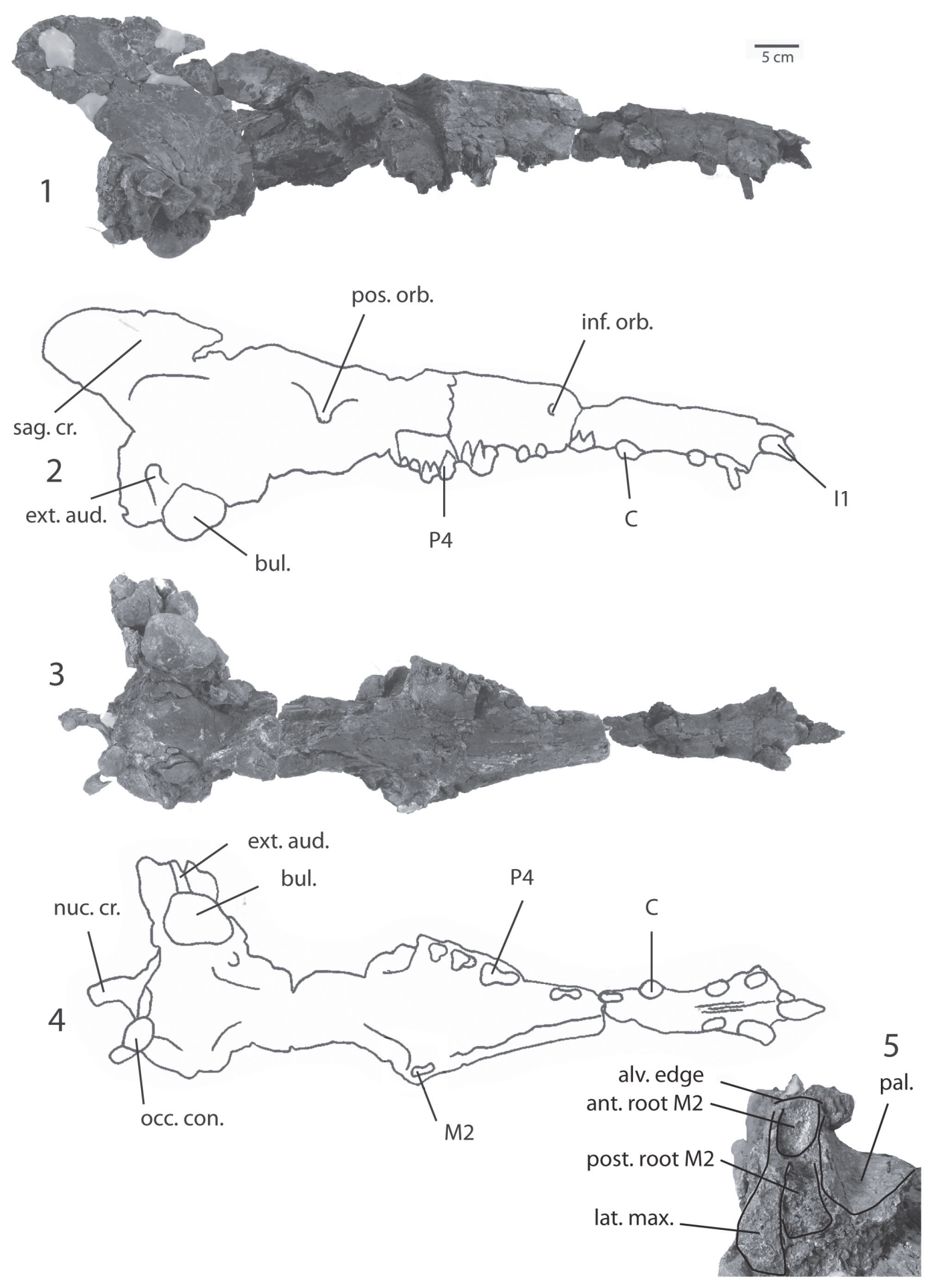

FIGURE 5. Dhedacetus hyaeni. IITR-SB 2870, holotype skull. 1-2, right lateral view and its outline drawing. 3-4, ventral view and its outline drawing. 5, detail of caudal view of right maxilla with M2 roots, lateral to left, ventral to top. Abbreviations: alv. edge, edge of alveolar process of M2; ant. root M2, anterolabial root of M2; bul., bulla; ext. aud., external auditory meatus; lat. max., broken edge of maxilla lateral to molar roots; nuc. cr., nuchal crest; occ. con., occipital condyle; pal., palate, medial to teeth; pos. orb., postorbital process; post. root M2, posterolabial root of M2. Abbreviations for teeth (I1, C, P4, M2) refer to wns or roots preserved. Scale bar pertains to 1 through 4. 


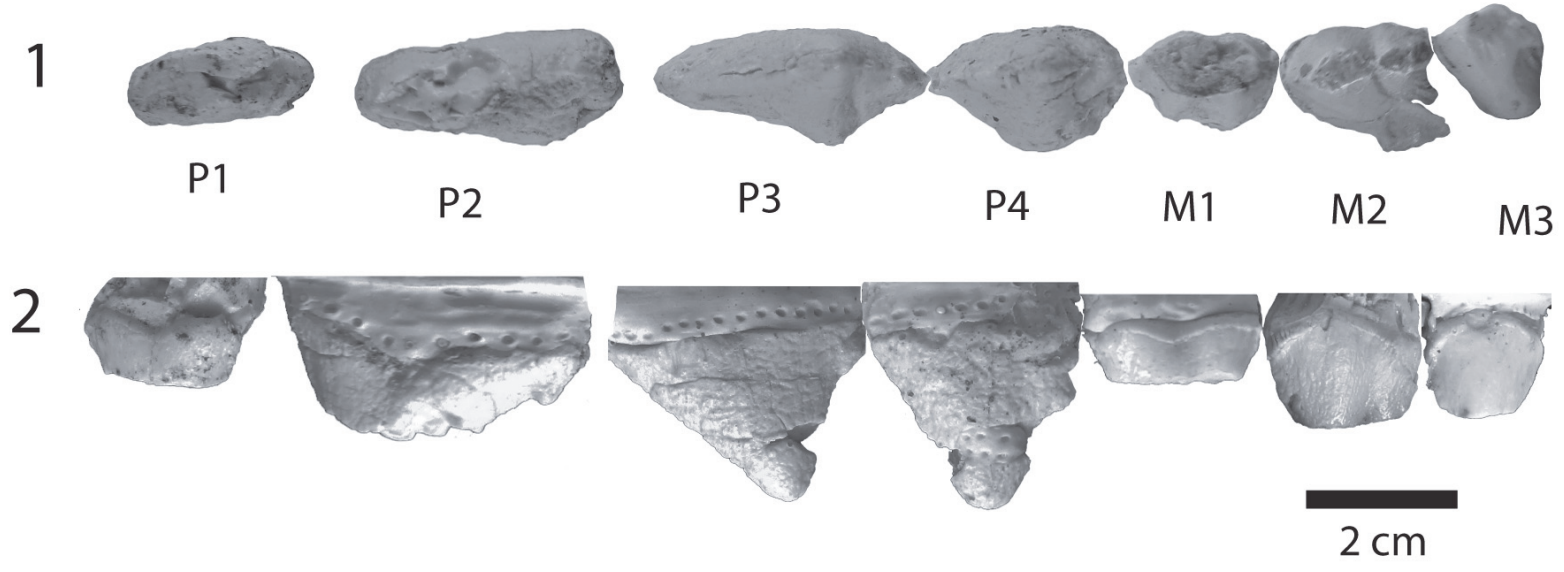

FIGURE 6. Dhedacetus hyaeni, IITR-SB 2870, upper teeth of holotype in occlusal (1) and labial (2) view. Crowns were in place when specimen was found, but were detached from skull in collecting and have not been reattached to the skull because of their fragility.

crest, and at the rostral end of this crest is the suture between frontal and parietal. The dorsal part of the sagittal crest is severed from the braincase and shows the impression of the tunnel for the olfactory stalk. Caudally, the sagittal crest is continuous with the left and right nuchal crests, which extend caudally beyond the occiput. The nuchal crests form a half-tubular shape in caudal view.

The squamosal forms the lateral side of the braincase, and a break exposes its contact with parts of the petrosal and mastoid. The right tympanic is large and is suspended from the base of the braincase. The external auditory meatus extends caudo-dorsally, and indents the paraoccipital process. The left tympanic was recovered detached from the skull and remains unattached. The ventral side of the tympanic is grooved and there is an involucrum.

Several tooth crowns are present in the upper jaw (Figure 6), and several others were found near the skull. I1 and I2 are single-rooted, conical teeth, 11 projects rostral curving down, while 12 projects down. $\mathrm{I} 3$ is single rooted and smaller than the other incisors. Tooth wear occurs on 12 and 13 , the crown of $\mathrm{I} 1$ is damaged. The base of the canine is preserved, and its size suggests that this tooth was similar in size to I2. P1 is double-rooted, its crown heavily worn. P2 has two widely spaced roots, its crown is a low triangle, and its protocone is placed well anterior to the middle of the tooth. A cusp, smaller than the main cusp, occurs on the crest that descends the protocone caudally. P3 is also a triangle, higher than $\mathrm{P} 2$, with the protocone placed caudal to the middle of the tooth. There is a lingual bulge and the crest that descends the protocone caudally bears a metacone. P4 is similar to P3, except for being a shorter tooth, making pre- and postparacrista steeper than in $\mathrm{P} 3$. The metacone is larger than in P3. Among the molars, M2 and M3 are best preserved. They have a protocone lobe, but it is unclear whether it bore a protocone, since there is extensive wear. The protocone lobe is positioned at the caudal side of the tooth. M2 bears a large paracone and smaller metacone. Both of these cusps can also be recognized in $M 3$, but the metacone is fused into the paracone. M3 is much smaller than M2. Both teeth have a cingulum rostrally, caudally and labially, while a lingual cingulum cannot be seen, as this area is obscured by wear. M1 is worn and broken, but appears to have been similar to M2.

Approximately 29 vertebrae or parts thereof are part of IITR-SB 2870. Most of these are large, and match the size that would be expected for the skull of Dhedacetus, based on protocetids such as Maiacetus, were skulls and vertebrae are known. In Dhedacetus, some of the vertebrae were arranged in situ in anatomical position, and were excavated and numbered to keep track of their order. These vertebrae included thoracic, lumbar and caudal vertebrae. Weathering disturbed the position the rest of the vertebral column, and some of the disturbed vertebrae were found on the surface. Mixed among these large vertebrae, there are three fossils that are differently preserved, more weathered and different in color, and pertaining to a much smaller individual. These include a cervical and a thoracic vertebra, as well as a 


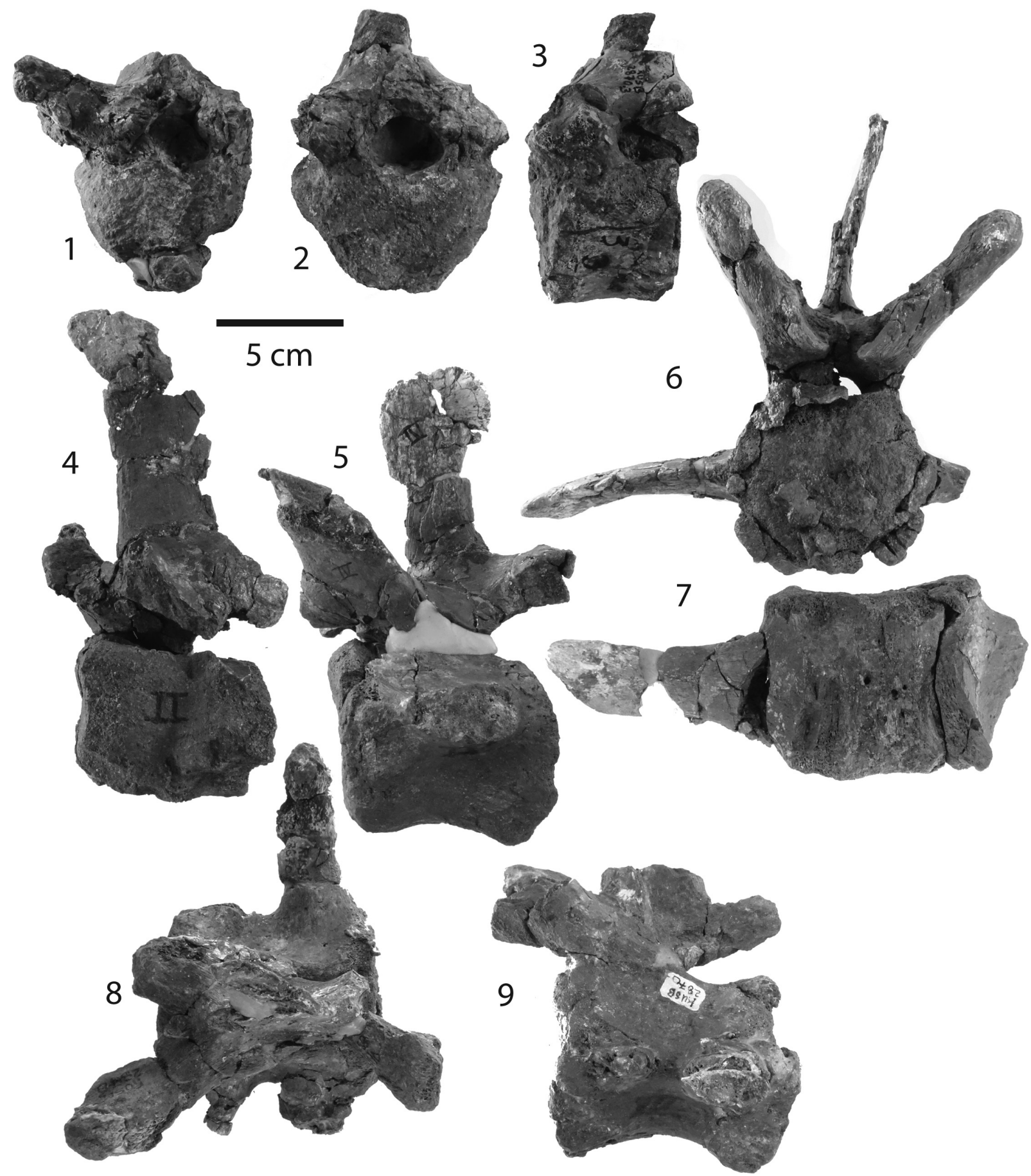

FIGURE 7. Dhedacetus hyaeni, IITR-SB 2870, holotype. 1, mid-thoracic vertebra in anterior view (2870.8). 2-3, midthoracic vertebra in anterior view and lateral view (2870.3). 4-5, anterior caudal vertebrae in lateral view (2870.II and IV), 6-7, anterior caudal vertebra in anterior and ventral view (2870.V). 8-9, anterior caudal vertebra in dorsal and lateral view (2870. VIII and VII).

sacrum. These fossils probably pertain to a remingtonocetid, and the sacrum matches that of Remingtonocetus as described by Bebej et al. (2012).
Pieces of 11 thoracic vertebrae of the type specimen of Dhedacetus were found (Figure 7 , Table 2), including an articulated set of two (labelled IITR-SB 2870.A and B), and another artic- 
TABLE 2. Vertebral measurements (in $\mathrm{mm}$ ) for Dhedacetus, first column for each identifies caudal vertebra.

\begin{tabular}{c|cccc|cccc} 
& \multicolumn{7}{|c}{ IITR-SB 2625 } & \multicolumn{5}{c}{ IITR-SB 2870 } \\
caudal vertebral level & length & width & height & $\begin{array}{c}\text { specimen } \\
\text { number }\end{array}$ & length & width & height & $\begin{array}{c}\text { specimen } \\
\text { number }\end{array}$ \\
\hline 1 & 59 & 70 & 51 & 2625.0 & & & & \\
2 & 63 & 68 & 50 & 2625.5 & 55 & & 50 & $2870 . I I$ \\
3 & 68 & 66 & 55 & 2625.1 & 57 & 71 & 55 & $2870 . I I I$ \\
4 & 71 & 63 & 57 & 2625.2 & 62 & 64 & 57 & $2870 . I V$ \\
5 & 71 & 64 & 59 & 2625.3 & 66 & 64 & 54 & $2870 . V$ \\
7 & 76 & 64 & 56 & 2625.4 & 67 & 59 & 55 & $2870 . \mathrm{VI}$ \\
8 & 76 & 63 & 62 & 2625.6 & 74 & 63 & 57 & $2870 . \mathrm{VII}$ \\
10 & 76 & 63 & 58 & 2625.7 & 73 & 62 & 57 & $2870 . \mathrm{VIII}$ \\
& 75 & 62 & 62 & 2625.8 & & & &
\end{tabular}

ulated set of nine (labelled IITR-SB 2870.1-9), that included some rib fragments. The centra of these vertebrae are heart-shaped, and the neural canal is smaller than in Ambulocetus (Madar et al., 2002). Transverse processes project dorso-lateral and bear a costal facet. Posterior articular facets face due ventral. The spinous process is as robust as Ambulocetus, but is not preserved in its entirety in any of these vertebrae. Rib fragments are flat and not pachyostotic. The head and tubercles of the rib are widely separated indicating that these are anterior and mid thoracic vertebrae.

Centra of six lumbar vertebrae were recovered. These centra are wider than high, and their anterior and posterior surfaces are concave. The root of the transverse process differs in thickness, it is thin (dorsoventrally) in most of these, but thick in one of them.

Seven caudal vertebrae were found in anatomical position and were labelled IITR-SB 2870.IIVIII. Several of these vertebrae are nearly complete with the neural arch, articular processes and spinous process. The centrum of these vertebrae is oval in the anterior vertebrae and more or less circular in the posterior ones. The transverse process emanates from the middle of the vertebral centrum. These processes are shorter in more posterior vertebrae. In vertebra IITR-SB2870.II through $V$ there is a single transverse process, whereas vertebrae IITR-SB 2870.VII and VIII have an anterior and a posterior transverse process. In vertebra IITR-SB $2870 . \mathrm{VI}$, the root of the transverse process is longer (anteroposteriorly) than in the others, and a small depression occurs in its middle. In vertebra IITR-SB 2870.II, the posterior epiphysis is missing. The spinous process of the caudal vertebrae is more slender and is angled anteriorly. This process is long in the anterior vertebrae and gradually shortens posteriorly. Anterior articular processes extend antero-dorsally. These are much longer than the posterior articular processes.

An isolated tail fragment of Dhedacetus (IITRSB 2625; Figure 8) consists of 10 caudal vertebrae that were found articulated in the field. Morphologically, these match the caudal vertebrae of IITR-SB 2870 , and we therefore assume that they cover the same part of the tail. Most diagnostic is the shape of the root of the transverse processes, including the transition from a single to two transverse processes. This leads us to infer that vertebra IITR-SB 2870.VI is homologous to IITR-SB 2625.4. In Maiacetus, the fourth caudal vertebra is the most anterior vertebra with divided transverse processes (Gingerich et al., 2009). In Dhedacetus, there are five caudal vertebrae anterior to the first vertebra with divided transverse processes, so we assume that this is caudal vertebra 6 , and that the entire anterior caudal column is preserved. A V-shaped hemal arch was attached to the posterior part of the one of the ventral bodies (IITR-SB 2625.6). The most anterior vertebra in this series lacks a posterior epiphysis. Anatomical position for IITR-SB 2625.5 was lost during preparation and is not included in Figure 8, and its level is inferred from morphology in Table 2.

Discussion. Dhedacetus hyaeni is the smallest protocetid from Kutch, but the only one for which a significant section of the vertebral column is known. We refer a single specimen to the new spe- 


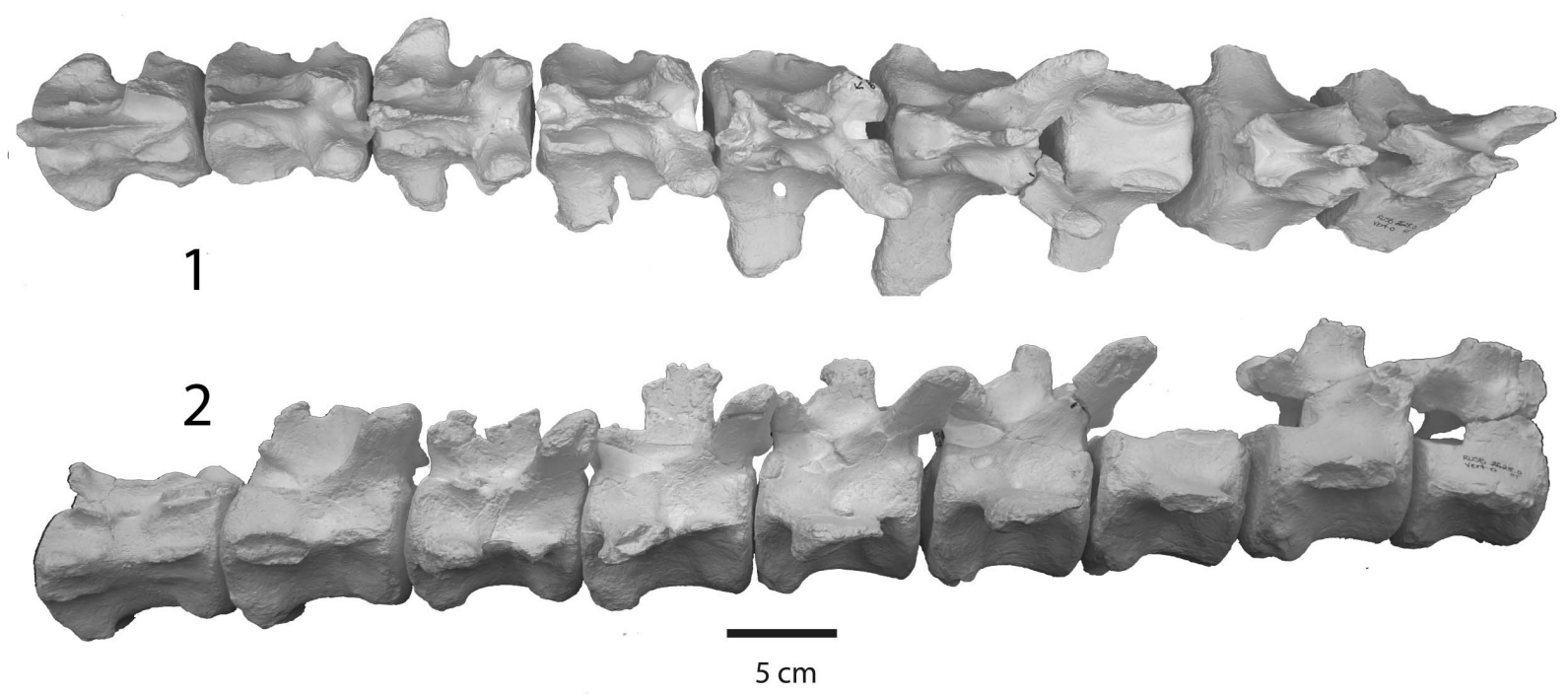

FIGURE 8. Dhedacetus hyaeni. 1-2, articulated caudal vertebrae of referred specimen (IITR-SB 2625) in left labial and dorsal view, respectively. Rostral is to right.

cies (IITR-SB 2625), a series of caudal vertebrae that matches the caudal vertebrae of the holotype in size and shape. Multiple articulated tail vertebrae are not available for any other Indian protocetid, but, until shown otherwise, we assume that the skulls and teeth of these protocetids are a guide to the size of their tail vertebrae. Based on this, IITR-SB 2625 pertains most likely to Dhedacetus.

A number of articulated tail vertebrae was found for Pakistani Maiacetus (Gingerich et al., 2009). Caudal vertebrae 1-3 have a single transverse process, whereas caudal vertebra 4-6 have two transverse processes (Gingerich et al., 2009). We used this similarity to identify, tentatively, the vertebral levels of the Dhedacetus specimens.

\section{DISCUSSION}

\section{Deciduous Dentition}

Morphologically, the new protocetid specimens from Kutch are intriguing because they reveal the morphology of dp4. Among Eocene cetaceans, deciduous lower premolars are only known in pakicetids (Thewissen and Hussain, 1998), protocetids (Barnes and Mitchell, 1978) and basilosaurids (Kellogg, 1936; Uhen, 2004). In pakicetids, dp4 bears three cusps, lined up antero-posteriorly, and the second of these is the largest, and is reminiscent of a dp4 of an artiodactyl where metaconid and entoconid were lost. This is very different from the pakicetid p4, which consists of a single, large, triangular cusp. In basilosaurids, dp4 and p4 are similar in shape, a number of cusps lined up from anterior to posterior where a cusp near the middle of the tooth is the highest, and cusps decrease in size as they are further from the main cusp. No p4 is known for Indocetus, but, given the p4 morphology of other protocetids as well as pakicetids and ambulocetids, it was probably triangular in labial view with a single high cusp. Surprisingly, but consistent with other protocetids (Barnes and Mitchell, 1978), its deciduous precursor consists of a shape that is reminiscent of the basilosaurid dp4 in having multiple cusps of decreasing size descending from the protonid posteriorly and a single, low cusp, anterior to the protoconid. The variation in these tooth shapes cannot be interpreted functionally at this point, but suggests evolutionary experimentation in Eocene cetacean dentitions.

\section{Tail Evolution}

The preserved tail fragments of Dhedacetus are incomplete but do contribute to our understanding of the origin of tail-based locomotion in cetaceans. The presence of caudal vertebrae with large spinous and transverse processes in Dhedacetus suggests that epaxial and hypaxial muscle bundles were large and consistent with tail-based 
propulsion. In modern cetaceans, the tail bears a fluke, and this is the main organ of propulsion, as it is used in dorsoventral oscillation (Fish, 1996). There is agreement that basilosaurid cetaceans also had a fluke (Buchholtz, 1998; Uhen, 2004, 2014a; Gingerich et al., 2009), but the fluke was absent in pakicetids, ambulocetids and remingtonocetids (Madar, 2007; Madar et al., 2002; Thewissen and Bajpai, 2009), and a variety of other swimming methods has been hypothesized to occur among Eocene cetaceans (Thewissen and Fish, 1997; Gingerich, 2003; Thewissen and Taylor, 2007). It has been proposed that a fluke was present in some protocetids (Gingerich et al., 2001b), but also that it was absent (Buchholtz, 1998). The origin of the fluke is broadly contemporaneous with the loss of a weight bearing sacrum (Moran et al., 2014; Uhen, 2014a), but the two may not be functionally correlated. Uhen (2014a) reviewed all evidence explicitly and suggested that no protocetid had a fluke. Unfortunately, associated tails are known for very few protocetids, so no broad comparative study of their tails is possible.

There are several osteological correlates of a fluke, even though the lateral wings of the fluke lack bone and do not fossilize. Uhen (2004) discussed morphological features of the ball vertebra in basilosaurids, which is located in the peduncle. Buchholtz (1998) found that the height/width proportions of the vertebral centrum differ between the peduncle and the areas cranial and caudal to it. Indeed, similar differences in proportions occur in dugongs, which are fluked, but not in manatees, which have a paddle tail. In the basilosaurid Zygorhiza, centrum height/width proportions suddenly change along the tail (Buchholtz, 1998), indicating that this taxon had a fluke, and the same is true in Dorudon (Uhen, 2004). Buchholtz (1998) studied vertebral proportions for Rodhocetus and found that these indicate that no fluke is present. In contrast, Gingerich et al. (2009) published vertebral dimensions for Maiacetus, and its $13^{\text {th }}$ caudal vertebra is higher than wide, whereas vertebrae caudal to it are wider than high. This is consistent with the presence of a peduncle and fluke. Evaluation of this specimen for the presence of a ball vertebra could be used to further investigate this.

\section{Paleoecology}

A variety of marine environments occurred in the Eocene of Kutch, including tidal flats, reefs and seagrass meadows (Thewissen and Bajpai, 2009). Protocetids are found in all these environments, but they are rare in the coastal swamp environ- ments of the localities Babia Hill and Panandhro. The remingtonocetid whales Andrewsiphius and Kutchicetus are common here, further emphasizing the ecological differences between and within families of middle Eocene cetaceans in India.

The protocetids from Kutch are taxonomically and morphologically diverse. Molar morphology is similar among them, but there are distinct differences in size of the premolars and jaws, as was already noted by Gingerich et al. (2001b) for Pakistani protocetids. Differences in tooth and jaw morphology, as well as in tooth wear suggest that there was a range of diets and food processing abilities among them, although at present, hypotheses regarding this are difficult to test.

The diversity of protocetids from Eocene Kutch is well understood. Dhedacetus hyaeni is the smallest species, followed by Indocetus ramani. Their dentition and tooth wear, as far as it is known, is consistent with a diet of soft invertebrates or fish. It is possible that these species had different diets or hunting habits. This may be reflected in the shape of the preorbital region: the orbit is high in Dhedacetus and low in Indocetus. Indocetus is relatively common at the locality Rato Nala (Thewissen and Bajpai, 2009). This locality faced the open ocean, and its sediments were deposited in clear water. This is consistent with the interpretation that Indocetus was a coastal hunter, which used its big eyes and sophisticated hearing to find prey.

Babiacetus is larger than Indocetus and Dhedacetus. Thewissen et al. (2011) pointed out that the molar wear in Babiacetus differed from that of other protocetids, suggesting differences in diet. Although it is likely that all Kutch protocetids pursued live prey, Babiacetus may have hunted prey that was harder or struggled more than the smaller species of protocetids. The long, fused mandibular symphysis of Babiacetus also suggests that the jaw was subjected to greater forces.

Kharodacetus is the largest protocetid from Kutch and may have fed on the largest prey. Large vertebrates in Kutch include crocodilians, large fish, such as catfish, and other cetaceans, such as remingtonocetids, and it is certainly possible that Kharodacetus hunted these. A remingtonocetid sacrum found with the skeleton of Dhedacetus may be evidence of a predation event. Isotope analysis may be able to determine dietary differences between these taxa.

\section{CONCLUSION}

The protocetid fauna from Kutch was diverse, containing a variety of genera, with different eco- 
logical specializations. In abundance, they were rarer than the contemporaneous remingtonocetids, which is not surprising since they fed higher up the food chain. Protocetids from Kutch are less diverse than those from the Pakistani Sulaiman Range, possibly because localities from the latter area sampled a longer time period than those from Kutch.

\section{ACKNOWLEDGEMENTS}

We thank the Department of Science and Technology, Government of India for financial support (grants to S. B. from 2007-2010) and the National Science Foundation of the U.S. (Earth Sciences) for funding this research (grant to J.T.).

\section{REFERENCES}

Bajpai, S. and Thewissen, J.G.M. 1998. Middle Eocene cetaceans from the Harudi and Subathu Formations of India, p. 213-233. In Thewissen, J.G.M. (ed.), The Emergence of Whales, Evolutionary Patterns in the Origin of Cetacea. Plenum Press, New York.

Bajpai, S. and Thewissen, J.G.M. 2000. A new, diminuitive whale from Kachchh (Gujarat, India) and its implications for locomotor evolution of cetaceans. Current Science (New Delhi), 79:1478-1482.

Bajpai, S., Thewissen, J.G.M., and Conley, R.W. 2011. Cranial anatomy of middle Eocene Remingtonocetus (Cetacea, Mammalia). Journal of Paleontology, 85:703-718.

Bajpai, S., Thewissen, J.G.M., and Sahni, A. 1996. Indocetus (Cetacea, Mammalia) endocasts from Kachchh (India). Journal of Vertebrate Paleontology, 16:582-584.

Barnes, L.G. and Mitchell, E.D. 1978. Cetacea, p. 582602. In Maglio, V.J. and Cooke, H.B.S. (eds.), Evolution of African Mammals. Harvard University Press, Cambridge.

Bebej, R.M., u.-Haq, M., Zalmout, I.S., and Gingerich, P.D. 2012. Morphology and function of the vertebral column in Remingtonocetus domandaensis (Mammalia, Cetacea) from the middle Eocene Domanda Formation of Pakistan. Journal of Mammalian Evolution, 19:77-104. DOI 10.1007/s10914-011-9184-8.

Bianucci, G. and Gingerich, P.D. 2011. Aegyptocetus tarfa, n. gen. et sp. (Mammalia, Cetacea), from the middle Eocene of Egypt: clinorhynchy, olfaction, and hearing in a protocetid whale. Journal of Vertebrate Paleontology, 31:1173-1188.

Brisson, M.J. 1762. Regnum animale in classes IX distributum, sive synopsis methodica classium, quadripedum scilicet \& cetaceorum, particularum divsionem in ordines, sectiones, genera, \& species. Editio altera auctior. Theodorum Haak, Lugduni Batavorum, Leiden.
Buchholtz, E.A. 1998. Implications of vertebral morphology for locomotor evolution in early cetaceans, $p$. 325-352. In Thewissen, J.G.M. (ed.), The Emergence of Whales, Evolutionary Patterns in the Origin of Cetacea. Plenum Press, New York.

Fish, F.E. 1996. Transitions from Drag-based to Liftbased Propulsion in Mammalian Swimming. American Zoologist, 36:628-641.

Geisler, J., Sanders A.E., and Luo, Z.-X. 2005. A new protocetid whale (Cetacea: Archaeoceti) from the late middle Eocene of South Carolina. American Museum Novitates, 3480:1-65.

Gingerich, P.D. 2003. Land-to-sea transition or early whales: evolution of Eocene Archaeoceti (Cetacea) in relation to skeletal proportions and locomotion of living semiaquatic mammals. Paleobiology, 29:429454.

Gingerich, P.D. and Cappetta, H. 2014. A new archaeocete and other marine mammals (Cetacea and Sirenia) from the lower middle Eocene phosphate deposits of Togo. Journal of Paleontology, 88:109129.

Gingerich, P.D., Arif, M., and Clyde, W.C. 1995b. New archaeocetes (Mammalia, Cetacea) from the middle Eocene Domanda Formation of the Sulaiman Range, Punjab (Pakistan). Contributions from the Museum of Paleontology, University of Michigan, 29:291-330.

Gingerich, P.D., Ul-Haq, M., Khan, I.H., and Zalmout, I.S. 2001a. Eocene stratigraphy and archaeocete whales (Mammalia, Cetacea) of Drug Lahar in the Eastern Sulaiman range, Balochistan (Pakistan). Contributions from the Museum of Paleontology, University of Michigan, 30:269-319.

Gingerich, P.D., Zalmout, I.S., UI-Haq, M., and Bhatti, M.A. 2005. Makaracetus bidens, a new protocetid archaeocete (Mammalia, Cetacea) from the early middle Eocene of Balochistan (Pakistan). Contributions from the Museum of Paleontology, University of Michigan, 31:197-210.

Gingerich, P.D., Arif, M., Bhatti, M.A., Raza, H.A., and Raza, S.M. 1995a. Protosiren and Babiacetus (Mammalia, Sirenia and Cetacea) from the middle Eocene Drazinda Formation, Sulaiman Range, Punjab (Pakistan). Contributions from the Museum of Paleontology, University of Michigan, 29:331-357.

Gingerich, P.D., Raza, S.M., Arif, M., Anwar, M., and Zhou, X. 1993. Partial skeletons of Indocetus ramani (Mammalia, Cetacea) from the lower middle Eocene Domanda Shale in the Sulaiman Range of Punjab (Pakistan). Contributions from the Museum of Paleontology, University of Michigan, 28:393-416.

Gingerich, P.D., Raza, S.M., Arif, M., Anwar, M., and Zhou, X. 1994. New whale from the Eocene of Pakistan and the origin of cetacean swimming. Nature, 368:844-847.

Gingerich, P.D., Ul-Haq, M., Zalmout, I.S., Khan, I.H., and Malkani, M.S. 2001b. Origin of whales from early artiodactyls: hands and feet of Eocene Protocetidae from Pakistan. Science, 293:2239-2242. 
Gingerich, P.D., UI-Haq, M., von Koenigswald, W., Sanders, W.J., Smith, B.H., and Zalmout, I.S. 2009. New protocetid whale from the middle Eocene of Pakistan: birth on land, precocial development, and sexual dimorphism. PLoS One 4:e4366. DOI:10.1371/journal.pone. 0004366 .

Hulbert, R.C., Jr. 1998. Postcranial osteology of the North American middle Eocene protocetid Georgiacetus, p. 235-267. In Thewissen, J.G.M. (ed.), The Emergence of Whales, Evolutionary Patterns in the Origin of Cetacea. Plenum Press, New York.

Hulbert, R.C., Jr., Petkevich, R.M., Bishop, G.A., Burky, D., and Aleshire, D.P. 1998. A new middle Eocene protocetid whale (Mammalia: Cetacea: Archaeoceti) and associated biota from Georgia. Journal of Paleontology, 72:905-925.

Kellogg, R. 1936. A Review of the Archaeoceti. Carnegie Institution of Washington, Publication, 482:1-366.

Kumar, K. and Sahni, A. 1986. Remingtonocetus harudiensis, new combination, a middle Eocene archaeocete (Mammalia, Cetacea) from Western Kutch, India. Journal of Vertebrate Paleontology, 6:326-349.

Linnaeus, C. 1758. Systema naturae per regna tria naturae, secundum classes, ordines, genera, species, cum characteribus, differentiis, synonymis, locis. Tomus I. Editio duodecima, reformata. Impensis Direct. Laurentii Salvii, Holmiae, Stockholm.

Madar, S.I. 2007. The postcranial skeleton of early Eocene pakicetid cetaceans. Journal of Paleontology, 81:176-200.

Madar, S.I., Thewissen, J.G.M., and Hussain, S.T. 2002. Additional holotype remains of Ambulocetus natans (Cetacea, Ambulocetidae), and their implications for locomotion in early whales. Journal of Vertebrate Paleontology, 22:405-422.

Moran, M.M., Bajpai, S., George, J.C., Suydam, R., Usip, S., and Thewissen, J.G.M. 2014. Intervertebral and epiphyseal fusion in the postnatal ontogeny of cetaceans and terrestrial mammals. Journal of Mammalian Evolution DOI 10.1007/s10914-014-9256-7.

Nummela, S., Thewissen, J.G.M., Bajpai, S., Hussain, S.T., and Kumar, K. 2004. Eocene evolution of whale hearing. Nature, 430:776-778.

Nummela, S., Thewissen, J.G.M., Bajpai, S., Hussain, S.T., and Kumar, K. 2007. Sound transmission in archaic and modern whales: anatomical adaptations for underwater hearing. Anatomical Record, 290:716733.

Ravikant, V. and Bajpai, S. 2010. Strontium isotope evidence for the age of Eocene fossil whales of Kutch, western India. Geological Magazine, 147:473-477.

Sahni, A. and Mishra, V.P. 1975. Lower Tertiary vertebrates from Western India. Palaeontological Society of India, Monograph, 3:1-48.

Spoor, F., Bajpai, S., Hussain, S.T., Kumar, K., and Thewissen, J.G.M. 2002. Vestibular evidence for the evolution of aquatic behaviour in early cetaceans. Nature, 417:163-166.
Stromer, E. 1908. Die Archaeoceti des Ägyptischen Eozäns. Beiträge zur Paläontologie und Geologie Österreich-Ungarns und des Orients, 21:106-127.

Thewissen, J.G.M. and Bajpai, S. 2001. Whale origins as posterchild for macroevolution. BioScience, 5:10371049.

Thewissen, J.G.M. and Bajpai, S. 2009. New skeletal material of Andrewsiphius and Kutchicetus, two Eocene cetaceans from India. Journal of Paleontology, 83:635-663.

Thewissen, J.G.M. and Fish, F.E. 1997. Locomotor evolution in the earliest cetaceans: functional model, modern analogues, and paleontological evidence. Paleobiology, 23:482-490.

Thewissen, J.G.M. and Hussain, S.T. 1998. Systematic review of the Pakicetidae, Early and middle Eocene Cetacea (Mammalia) from Pakistan and India. Bulletin of the Carnegie Museum, 34:220-238.

Thewissen, J.G.M. and Hussain, S.T. 2000. Attockicetus praecursor, a new remingtonocetid cetacean from marine Eocene sediments of Pakistan. Journal of Mammalian Evolution, 7:133-146.

Thewissen, J.G.M. and Taylor, M.A. 2007. Aquatic adaptations in amniotes, p. 310-322. In Hall, B.K. (ed.), Fins into Limbs, Evolution, Development, and Transformation. University of Chicago Press, Chicago.

Thewissen, J.G.M., Clementz, M.T., Sensor, J.D., and Bajpai, S. 2011. Evolution of dental wear and diet during the origin of whales. Paleobiology, 37:655669.

Thewissen, J.G.M., Cooper, L.N, George, J.C., and Bajpai, S. 2009. From land to water: the origin of whales, dolphins, and porpoises. Evolution: Education and Outreach, 2:272-288.

Trivedi, A.N. and Satsangi, P.P. 1984. A new archaeocete (whale) from the Eocene of India. 27th Int. Geol. Congr. Abstract, 1:322-323.

Uhen, M.D. 2004. Form, function, and anatomy of Dorudon atrox (Mammalia, Cetacea): an archaeocete from the middle to late Eocene of Egypt. University of Michigan, Papers on Paleontology, 34:1-222.

Uhen, M.D. 2008. New protocetid whales from Alabama and Mississippi, and a new cetacean clade, Pelagiceti. Journal of Vertebrate Paleontology, 28:589-593.

Uhen, M.D. 2014a. New material of Natchitochia jonesi and a comparison of the innominate and locomotor capabilities of Protocetidae. Marine Mammal Science, 30:1029-1066. DOI: 10.1111/mms.12100.

Uhen, M. D. 2014b. New specimens of Protocetidae (Mammalia, Cetacea) from New Jersey and south Carolina. Journal of Vertebrate Paleontology, 34:211-219.

Uhen, M.D., Pyenson, N.D., Devries, T.J., Urbina, M., and Renne, P.R. 2011. New middle

Eocene whales from the Pisco Basin of Peru. Journal of Paleontology, 85:955-969. 
Williams, E.M. 1998. Synopsis of the earliest cetaceans: Pakicetidae, Ambulocetidae, Remingtonocetidae, and Protocetidae, p. 1-28. In Thewissen, J.G.M. (ed.), The Emergence of Whales, Evolutionary Patterns in the Origin of Cetacea. Plenum Press, New York. 